\title{
Colonization of Rice Roots by a Green Fluorescent Protein-Tagged Isolate of Ustilaginoidea virens
}

\author{
Mebeaselassie Andargie ${ }^{1 *}$, Luoye $\mathrm{Li}^{1}$, Aiqing Feng ${ }^{2}$, Xiaoyuan $\mathrm{Zhu}^{2}$, Jianxiong $\mathrm{Li}^{1}{ }^{*}$ \\ ${ }^{1}$ Key Laboratory of South China Agricultural Plant Molecular Analysis and Genetic Improvement, and \\ Guangdong Provincial Key Laboratory of Applied Botany, South China Botanical Garden, Chinese Academy of \\ Sciences, Guangzhou, China \\ ${ }^{2}$ Plant Protection Institute, Guangdong Academy of Agricultural Sciences, Guangzhou, China \\ Email: ${ }^{*}$ mebhel@yahoo.com, ${ }^{*}$ ixli@scbg.ac.cn
}

Received 7 August 2015; accepted 7 September 2015; published 10 September 2015

Copyright (C) 2015 by authors and Scientific Research Publishing Inc.

This work is licensed under the Creative Commons Attribution International License (CC BY).

http://creativecommons.org/licenses/by/4.0/

(c) (i) Open Access

\begin{abstract}
The fungus $U$. virens is the causal agent of rice false smut disease. The green fluorescent protein (GFP) was used to mark this fungus in order to visualize and analyze the colonization and infection processes in vivo. Using epifluorescence microscopy colonization and infection on rice roots were visualized in vivo. After inoculation for 2 to $15 \mathrm{~d}$, it was observed that the conidia and their germ-tubes had penetrated into epidermis of young roots. The hyphae were found inside the root xylem $18 \mathrm{~d}$ after inoculation. Generally, the transformed fungus colonized the rhizosphere, the cortex as well as the vascular tissues with symptoms of root necrosis observed. The results of this work show that $U$. virens colonize not only rice panicles but also the roots.
\end{abstract}

\section{Keywords}

Endophytes, Plant-Fungal Interactions, Rhizosphere, Root Colonization, Ustilaginoidea virens

\section{Introduction}

Rice (Oryza sativa L.) is an important cereal crop and staple food for a large number of populations all over the world. Its demand is increasing day by day with the increase in human population. Smut disease which is caused by the ascomycete fungus Ustilaginoidea virens (Cooke) Takah (Anamorph) is one of the potential threats to rice cultivation and causes severe yield losses of rice around the world [1]. The yield loss estimates ranged from

${ }^{*}$ Corresponding authors.

How to cite this paper: Andargie, M., Li, L.Y., Feng, A.Q., Zhu, X.Y. and Li, J.X. (2015) Colonization of Rice Roots by a Green Fluorescent Protein-Tagged Isolate of Ustilaginoidea virens. American Journal of Plant Sciences, 6, 2272-2279.

http://dx.doi.org/10.4236/ajps.2015.614230 
$2.8 \%$ to $81 \%$ in different rice-producing areas depending on the rice variety and disease intensity [2]-[4]. In addition to yield loss, $U$. virens also contaminates rice seed and straw by producing antimitotic cyclic peptides that are poisonous to both humans and animals [5] [6]. It was reported that $U$. virens which was able to reproduce both sexually and asexually with multiple propagules could be able to invade rice coleoptiles and roots at the young seedling stage and the stamen filaments at the earlier booting stage [7]-[9]. The disease cycle of Ustilaginoidea virens, which begins with the infection of plant tissues and culminates in new sporulation, has not been fully characterized [10]. In false smut, spore balls replace one or more kernels on mature heads as a result of infection of the plant. From one to more than 20 smut balls can be found on a single infected rice panicle. Spore balls can survive up to four months in soil and it is presumed that the sclerotia can survive much longer [10]. In addition, spores (sometimes called chlamydospores) found in the spore balls can produce one or more secondary spores after germination which are capable of infection.

A certain pathogen can be considered as either a "foliar/root pathogen" basically if it has the ability to colonize these tissues and also based on its ability to incite symptoms on leaves or roots rather than where infection occurs [11]. Characterizing the diverse interactions between the fungus and plant roots could help define the differences between pathogenic and nonpathogenic strains. Observing fungi in soil was very difficult and most of the studies describing the colonization of root surfaces by a fungus were carried out using hydroponic systems [12]-[14] or with a substrate such as sand or vermiculite [15]. Like most other pathogenic fungi, $U$. virens is able to survive in the soil and is extremely difficult to control. More detailed knowledge on the in vivo interactions between the pathogenic fungus and the plant could lead to the discovery of more efficient ways to control the disease. Details of these interactions can be essential in studies of the biological control of the fungus by beneficial antagonistic microorganisms that colonize the rice rhizosphere. The conventional methodologies used to study the interactions between pathogens and their host plants are not able to realize real-time and a live view of the fungal behaviors and the host reactions. The discovery of the fluoresent protein marker system offers a direct and non-destroyable way to analyze the systemic infection of fungi (especially for those soil-borne pathogens that are difficult to be observed) in their hosts in a dynamic mode [16]-[18].

The green fluorescent protein (GFP) from the jellyfish Aequorea victoria [19] [20] is a widely used reporter protein to facilitate the observation of hyphae on the root surface [21]. It was used to label $U$. virens in order to visualize by confocal laser scanning microscopy (CLSM) and epifluorescence microscopy the mode and path of infection in rice floral organs [22] [23]. GFP's fluorescence is stable and species independent and does not require any cofactors or substrates. In addition, visualization of GFP labeled organisms with epiflourescence microscopy and CLSM is an effective, fast, and noninvasive tool that allows the spatiotemporal analysis of interactions while preserving the integrity of the organisms under study or without destruction of the target tissues.

In a previous study, we generated $U$. virens strains expressing green fluorescence by introducing the GFP gene via Agrobacterium tumefaciens-mediated transformation (ATMT) [23]. Using a GFP-labeled fungal strain, this study was initiated to investigate the systemic infection and colonization of this fungus on/in rice roots.

\section{Materials and Methods}

\subsection{Fungal Strains and Inoculum Preparation}

The pathogenic strain Ustilaginoidea virens isolated from a diseased rice plant was transformed with the GFP gene as described previously by [23]. The transformed fungus strain was cultivated on a potato sucrose agar (PSA) at $28^{\circ} \mathrm{C}$ on a rotary shaker at $180 \mathrm{rpm}$. After 7 days of growth, fungal cultures were filtered through a sterile number 2 sintered-glass funnel (40- to $100-\mu \mathrm{m}$-pore-size mesh) to retain the mycelia. The microconidia remaining in the filtrate were harvested by centrifugation $\left(7500 \times \mathrm{g} ; 5 \mathrm{~min}\right.$ at $\left.24^{\circ} \mathrm{C}\right)$ and washed three times in sterile distilled water. The concentration of the conidial suspension was estimated under the microscope with a hemocytometer and adjusted as necessary with sterile distilled water $\left(10^{6}\right.$ microconidia $\left.\mathrm{ml}^{-1}\right)$.

\subsection{Plant Inoculation and Cultivation}

The rice cultivar Huangxiuzan, "HXZ" which is susceptible to false smut was grown in the experimental station of Plant Protection Institute, Guangdong Academy of Agricultural Science, Guangdong Province, China and used in this experiment. Before plant inoculation, the conidial viability of the fungus was checked according to the suggestion of [24]. Seeds were surface sterilized in $75 \%$ ethanol for $1 \mathrm{~min}$ and $1 \%$ sodium hypochlorite 
( $\mathrm{NaClO}$ ) for $5 \mathrm{~min}$, and thoroughly rinsed in distilled water five times. Seeds were germinated on sterile Whatman filter paper in petri dishes and incubated in the dark at $28^{\circ} \mathrm{C}$ for 6 days. When the third seedling leaves were unfolded, roots were dipped in a microconidial suspension for 1 and $1 / 2 \mathrm{~h}$. The density of the microconidial suspension was determined with a hemocytometer and adjusted by dilution to the desired concentration for root inoculation $\left(10^{6}\right.$ microconidia $\left.\mathrm{ml}^{-1}\right)$. Seedlings were aseptically transferred into tubes containing a sterile nu-

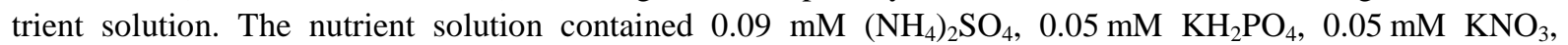
$0.03 \mathrm{mM} \mathrm{K}_{2} \mathrm{SO}_{4}, 0.06 \mathrm{mM} \mathrm{Ca}\left(\mathrm{NO}_{3}\right)_{2}, 0.07 \mathrm{mM} \mathrm{MgSO}_{4}, 0.11 \mathrm{mM} \mathrm{Fe}-\mathrm{EDTA}, 4.6 \mu \mathrm{M} \mathrm{H}_{3} \mathrm{BO}_{3}, 1.8 \mu \mathrm{M} \mathrm{MnSO}_{4}$, $0.3 \mu \mathrm{M} \mathrm{ZnSO}_{4}, 0.3 \mu \mathrm{M} \mathrm{CuSO}_{4}\left(\mathrm{pH}=5.5\right.$ - 6.0). The plants were cultivated in a growth chamber at $27^{\circ} \mathrm{C}$ during the day and $24^{\circ} \mathrm{C}$ at night. Control plants were dipped in sterile distilled water and then cultivated, as were the inoculated plants. Radicles were sampled after 24 hpi (hours post-inoculation) and a close observation of the different parts of the roots continued for six weeks. For this fungal strain which was under study, 16 inoculated plants and 8 control plants were processed for microscopic observations of root sections.

\subsection{Microscopic Observations}

Systemic colonization by $U$. virens in rice root tissues was determined at $1,2,3,4,5,10,15,18,21,24,27$ days and 4 weeks post-inoculation (dpi). Cross sections and longitudinal sections of tap and lateral roots were hand-sectioned and each placed directly on a glass slide in a water drop with a cover slip. Observation of the green fluorescence was conducted using an epifluorescence microscopy (LeicaDM6000 B) with excitation at 455 to $490 \mathrm{~nm}$ and emission at 515 to $560 \mathrm{~nm}$.

\section{Results and Discussion}

Plants are involved in mutualistic or parasitic interactions with a variety of micro-organisms, which has a strong impact on ecosystems, agriculture and forestry [25]-[28]. Generally, GFP-transformed pathogens can be easily visualized in living tissues without any further processing or manipulation of the samples and have a paramount importance in order to study the interaction of plants with different pathogenic organisms. In this study, a GFP-marked strain of $U$. virens was used to follow colonization of root tissues in HXZ, a susceptible rice variety. The use of a transformed isolate of $U$. virens, which is capable of expressing a GFP construct in conjunction with the appropriate illumination and optical filters allowed for easy discrimination of the fungus in planta, while requiring only minimal preparation of plant tissues. This property makes GFP-expressing strains extremely useful for analysis of in planta fungal development [29]. Fungal strains expressing fluorescent proteins have been used mainly to characterize their interactions with a plant [30]. Clone 40 was selected for the uniformity and strength of the resulting fluorescent signal in all fungal structures (Figure 1). Similar to other pathogenic fungi which were transformed with GFP [11] [31] [32], this clone was re-isolated from inoculated rice plants with no observable loss of GFP fluorescence or hygromycin B resistance, which confirmed the stability and robustness of the transformant.

Infection assay followed by a time course of microscopic observations was performed in order to determine whether $U$. virens could be able to infect and colonize itself on rice roots or not. The infection assays were performed with the HXZ-susceptible rice cultivar. Twenty-four hours after inoculation via the root-dipping method, roots were covered with conidia, of which only a small fraction exhibited signs of germination (Figure 2(a)). By $48 \mathrm{~h}$, at least half of the spores on root surfaces had germinated (Figure 2(b)). Germinating hyphae continued elongating parallel with the longitudinal axis of the root along the junctions of epidermal cells, which were evident by 72 h post-inoculation (Figure 2(c)). At this point, lateral, swellings could be seen at the junction between plant cells and on the root surface (Figure 2(c) and Figure 2(d)). More complex hyphal networks that form a net-like structure along the root epidermis grow within the grooves between epidermal cells after 5 dpi (Figure 2(d)). Conidia germinated to form hyphae instead of forming an appressoria like structure on the root surface even though spore suspensions were used as inoculum. A lot of hyphae colonized on and around the small lesions formed on rice roots, when the root tissues with lesions were observed under fluorescence microscope (Figure 2(e)). Generally, the hyphae always covered the regions beyond the lesions. Although the colonization of hyphae was observed on the large and greenish lesions, the extension of hyphae was limited inside the lesions (Figure 2(e)). Some lesions on rice roots were developed from the sites on the main roots where the root hairs were located (data not shown). 


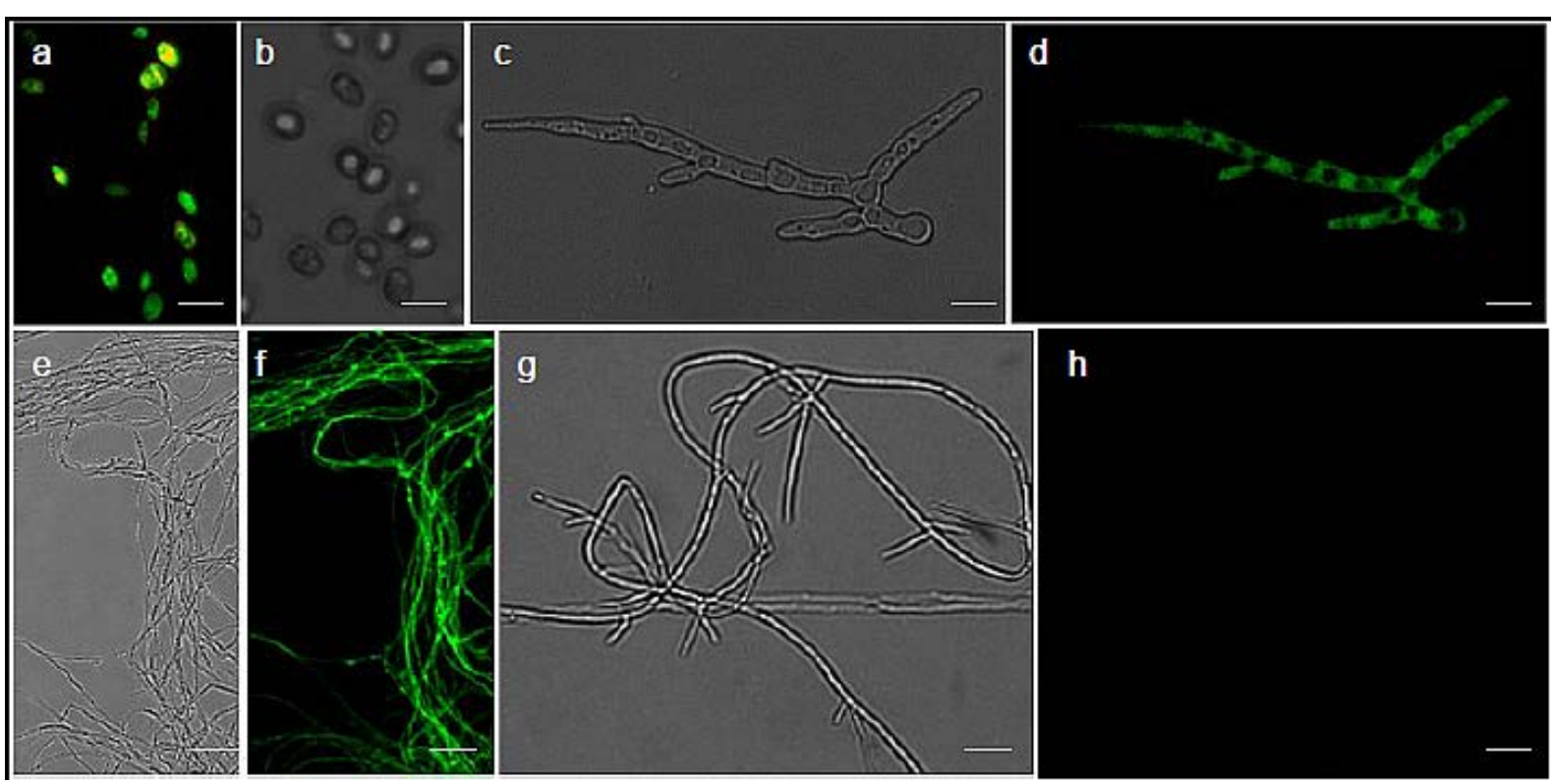

Figure 1. The GFP-tagged Ustilaginoidea virens strain. (a) Spore of the GFP-tagged fungus under epifluorescence microscopy; (b) Spore of the GFP-tagged fungus under bright field microscopy; (c) Germinating spore of the transformed fungus under bright field; (d) Germinating spore of the GFP-tagged fungus under epifluorescence microscopy; (e) Hypha of the transformed fungus under bright field microscopy; (f) Hypha of the GFP-tagged under epifluorescence microscopy; (g) Hypha of the wild fungus under bright field microscopy (h) Hypha of the wild fungus under epifluorescence microscopy. Each bar represents $100 \mu \mathrm{m}$.

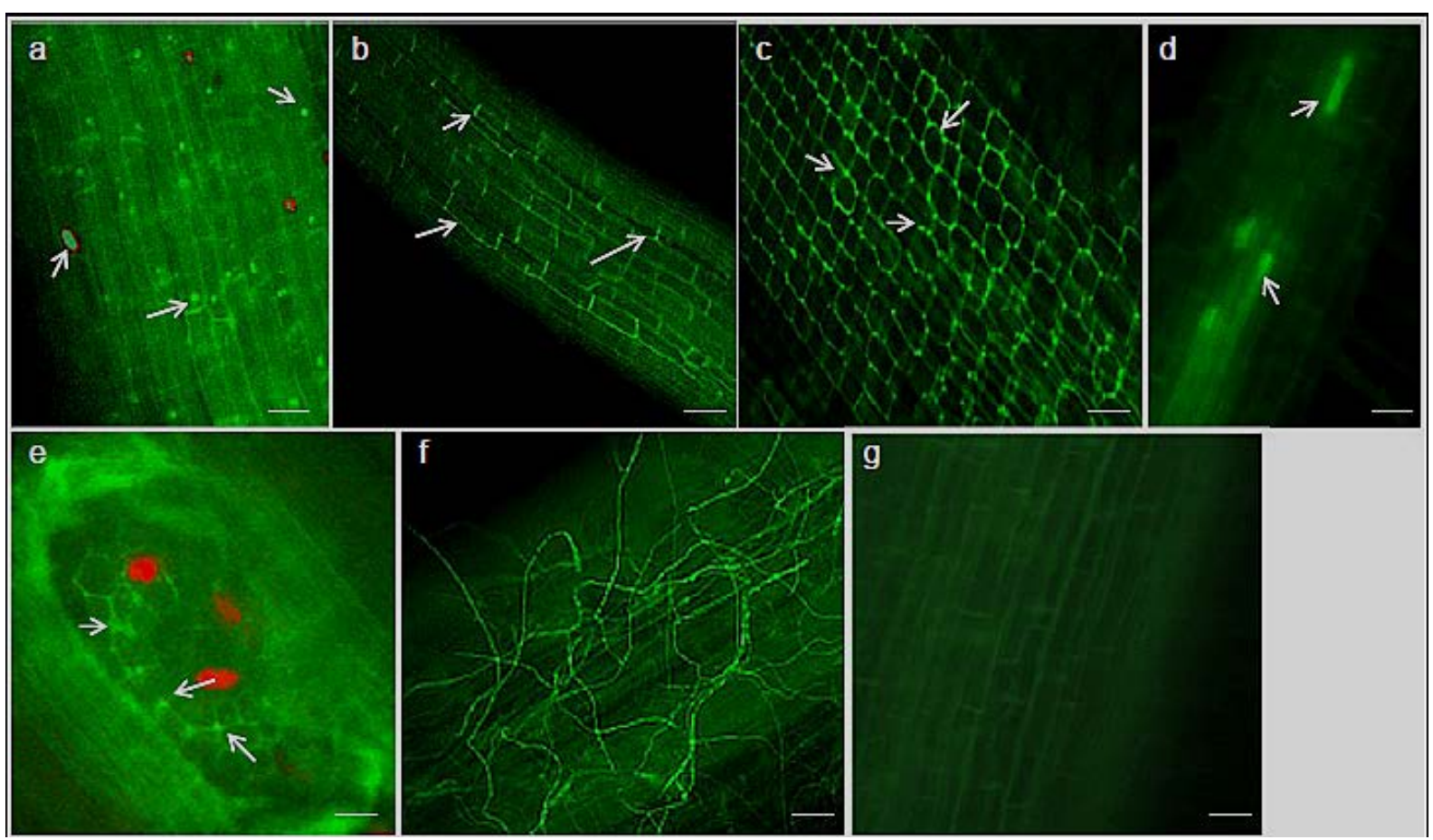

Figure 2. Early and late colonization stages of susceptible rice roots (HXZ) by GFP-tagged strains of $U$. virens. (a) spores of the GFP-tagged strains of $U$. virens after $1 \mathrm{dpi}$; (b) Fungal colonization on the rice root tended to form runner hyphae (arrow) $($ Bar $=100 \mu \mathrm{m})$; $(\mathrm{c})$ Growing hyphae forming a net-like structure on the root surface 4 dpi $($ Bar $=100 \mu \mathrm{m})$; $(\mathrm{d})$ Lesion formed on the adjacent region between main root and the fibrous root $(\mathrm{Bar}=100 \mu \mathrm{m})$; (e) Lesion formed on the region of the main root and the fungi located on the lesion $(\mathrm{Bar}=200 \mu \mathrm{m})$; $(\mathrm{f})$ Mycelium densely covering the main root after $15 \mathrm{dpi}(\mathrm{Bar}=$ $200 \mu \mathrm{m})$; (g) Control (Bar = $100 \mu \mathrm{m})$. 
The areas attacked formed brown lesions and the light brown color of lesions became dark brown (Figure 3(b)) and even black at later stages of infection. Finally, the root systems were full of lesions. Similar behavior of hyphae has been observed and reported for other root endophytes [33]-[35]. Once inside the root, the hyphae swelled and spread intracellularly into the cytosol of the cell through specific points of contact with other epidermal and cortical cells. At 15 dpi, hyphae were also observed invading the intercellular spaces of epidermal roots cells (Figure 2(f)). At 3 dpi, attachment had occurred along the root epidermis and after a successful penetration into the epidermal cells, the hyphae reached the vascular tissue intercellularly through the cortical cells then it continued to grow and ramify and lastly a hyphal net within the xylem vessels was observed by 18 dpi; this implies that penetration of the epidermis, cortex and the xylem took place between days 2 and 18. The rapid proliferation of hyphae within the xylem vessel cells mainly occurred longitudinally.

The hyphae appeared to be confined to the infected cell until the intracellular space was completely filled with hyphae. Only certain epidermal and cortical cells appeared to become colonized in this manner, while the surrounding cells remained uninfected, resulting in a mosaic pattern of plant cell colonization (Figure 2(d)). This pattern of plant cell colonization continued for 10 to 25 dpi. U. virens hyphae could be seen colonizing the surfaces of mature roots, lateral roots, root caps, root elongation zones, and root hairs (Figure 2), indicating that there was no specific root site preference.

Transverse sections from infected and uninfected roots were examined at various time points to determine the rates and extents of colonization. At $18 \mathrm{dpi}$, the pathogen colonized the epidermis and the cortical cells, both intercellularly and intracellularly (Figure 3(c)). Then later, the whole root cortex was heavily colonized, until the
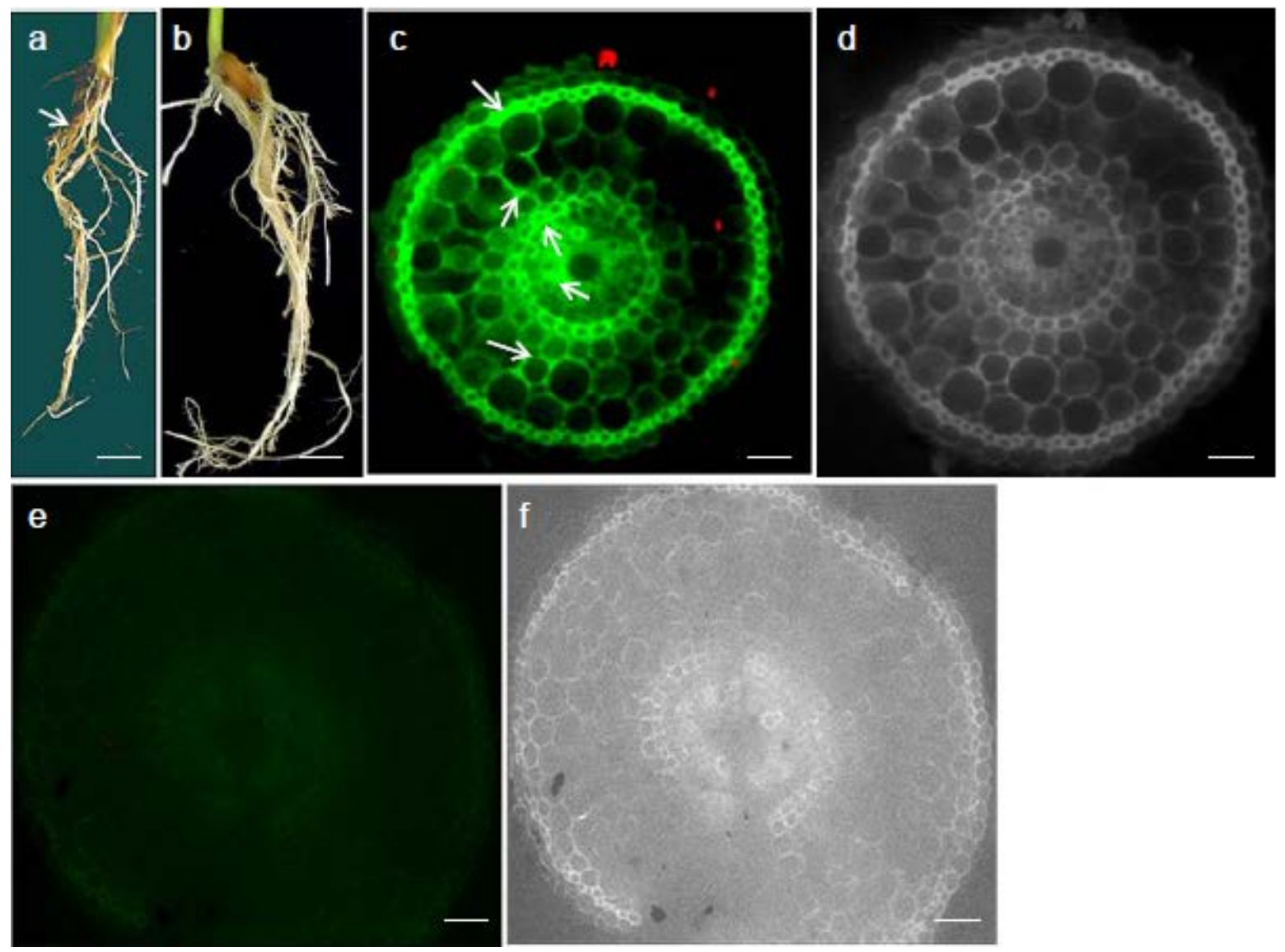

Figure 3. Systemic infection and colonization of GFP-tagged U. virens strain on the susceptible rice root (HXZ). (a) Symptoms on the root systems of rice following inoculation with GFP-tagged strain of $U$. virens on the elongation region (arrow) (Bar = $2 \mu \mathrm{m}$ ); (b) Uninfected 20-day-old rice root (Bar = $2 \mu \mathrm{m})$; (c) Cortical cells are colonized by hyphae and oval conidia (arrow) after $18 \mathrm{dpi}$ on a rice root cross section $($ Bar $=100 \mu \mathrm{m})$; (d) Cross section of the root observed in bright field $($ Bar = $100 \mu \mathrm{m})$; (e) Cross section of an uninfected 18-day-old rice root under epifluorescence microscopy $($ Bar $=100 \mu \mathrm{m})$; $(\mathrm{f})$ Cross section of the uninfected root observed in bright field $(\mathrm{Bar}=100 \mu \mathrm{m})$. 
fungus reached the endodermis (Figure 3(c)). The endodermis appeared to delay the progress of the hyphae, and it was not until 28 dpi that the fungus was observed colonizing the vascular cylinder (Figure 3(c)), where it could be observed colonizing the endodermis, sieve cells (phloem) and xylem. Even though xylem vessels were colonized by hyphae neither blockage of the vascular system nor did the plants exhibit wilting symptoms, typically found with vascular diseases from our observation. In the uninfected roots, light green auto-fluorescence was observed in the rice epidermis, phloem and xylem (Figure 3(e)).

Although the colonies of the transformed fungus in the cortex of rice were sparse, the hyphae was able to grow towards the vascular tissues with little hindrance. As colonization progressed in the lateral roots, two colonization fronts were clearly observed; one front enveloped the epidermis and cortical tissues and the other within the vascular tissues. The former brings the eventual collapse of the infected root tip whereas, the latter one continued its progression through infected xylem vessels of the infected lateral root from base to apex. There were no symptoms observed except the collapse of the root tip beyond the infection site as the mycelia advanced systemically through xylem vessels towards the taproot. Generally, from our observation, host penetration in most cases was through the intercellular space and it may also be through the junction that is formed between the root hairs and the lateral roots can be considered as another entry point for the fungus. Similar results were observed in rice, tomato and brassica on root infection and colonization by GFP-labeled Klebsiella, Fusarium and Verticilium respectively [15] [36] [37]. This could possibly be explained by the existence of a common mode of infection which is usually used by pathogens that attack vascular tissues to enter root hair zones. So the pathogens first attach and then penetrate directly into the epidermal cells, due to a stronger chemical attraction of the fungus to the root hairs than the root surface [30]. In this study, the hyphae grow irregularly on the root surfaces. The hyphae of most endophytes deviated from the direction along the root axes when they grew inside cells [38]. It is normal to see hyphae grew in irregular directions when they colonized living cells.

\section{Conclusion}

The present study, which is the first report of root colonization by the GFP-transformant of $U$. virens provides a new tool for studies of early endophyte root colonization stages and localization in the host tissue. Ustilaginoidea virens attacked rice roots by the initial infection of the root hairs, and then colonizing without killing them. In the susceptible rice cultivar HXZ, $U$. virens tended to form mosaic patterns of infection by filling individual cells with hyphae.

\section{Acknowledgements}

This work was supported by grants from the National Natural Sciences Foundation of China (911161001) and the Important Direction Research on Knowledge Innovation Project (KSCX2-EW-N-06) and the fund from Department of Agriculture of Guangdong Province awarded to J. X. Li. M. Andargie was a recipient of the "Visiting Fellowship for Researchers from Developing Countries” Award from Chinese Academy of Sciences.

\section{References}

[1] Tanaka, E., Ashizawa, T., Sonoda, R. and Tanaka, C. (2008) Villosiclava virens gen. nov., comb. nov., the Teleomorph of Ustilaginoidea virens, the Causal Agent of Rice False Smut. Mycotaxon, 106, 491-501.

[2] Singh, S., Pal, V. and Panwar, M. (1992) False Smut of Rice-Its Impact on Yield Components. Crop Research Hisar, 5, 246-248.

[3] Biswas, A. (2001) Field Reaction of Hybrid Rice Varieties to False Smut and Kernel Smut Disease in West Bengal India. Environment Ecology, 19, 299-230.

[4] Yang, L.M., Chen, L., Xu, J., Liu, J.C. and Ding, K.J. (2012) Estimation of Yield Loss Caused by Rice False Smut. Journal of Anhui Agricultural University, 39, 474-477.

[5] Koiso, Y., Li, Y., Iwasaki, S., Hanaoka, K., Kobayashi, T., Sonoda, R., Fujita, Y., Yaegashi, H. and Sato, Z. (1994) Ustiloxins, Antimitotic Cyclic Peptides from False Smut Balls on Rice Panicles Caused by Ustilaginoidea virens. Journal of Antibiotics, 47, 765-773. http://dx.doi.org/10.7164/antibiotics.47.765

[6] Luduena, R.F., Roach, M.C., Prasad, V., et al. (1994) Interaction of Ustiloxin A with Bovine Brain Tubulin. Biochemical Pharmacology, 47, 1593-1599. http://dx.doi.org/10.1016/0006-2952(94)90537-1

[7] Schroud, P. and TeBeest, D.O. (2005) Germination and Infection of Rice Roots by Spores of Ustilaginoidea virens. In: Norman, R.J., Meullenet, J.F. and Moldenhauer, K.A.K., Eds., University of Arkansas Agricultural Experiment Station 
Research Series, 540, 143-151. Fayetteville, Ark.

[8] Ashizawa, T., Takahashi, M., Arai, M. and Arie, T. (2012) Rice False Smut Pathogen, Ustilaginoidea virens, Invades through Small Gap at the Apex of a Rice Spikelet before Heading. Journal of General Plant Pathology, 78, 255-259. http://dx.doi.org/10.1007/s10327-012-0389-3

[9] Tang, Y.X., Jin, J., Hu, D.W., Yong, L.M., Xu, Y. and He, L.P. (2013) Elucidation of the Infection Process of Ustilaginoidea virens(Teleomorph: Villosiclava virens) in Rice Spikelets. Plant Pathology, 62, 1-8. http://dx.doi.org/10.1111/j.1365-3059.2012.02629.x

[10] Lee, F.N. and Gunnell, P.S. (1992) False Smut. In: Webster, R.K. and Gunnell, P.S., Eds., Compendium of Rice Diseases, American Phytopathological Society, St. Paul, Minn. Pg. 28.

[11] Sukno, S.A., Garcia, V.M., Shaw, B.D. and Thon, M.R. (2008) Root Infection and Systemic Colonization of Maize by Colletotrichum graminicola. Applied and Environmental Microbiology, 74, 823-832. http://dx.doi.org/10.1128/AEM.01165-07

[12] Olivain, C. and Alabouvette, C. (1997) Colonization of Tomato Root by a Non-Pathogenic Strain of Fusarium oxysporum. New Phytologist, 137, 481-494. http://dx.doi.org/10.1046/j.1469-8137.1997.00855.x

[13] Olivain, C. and Alabouvette, C. (1999) Process of Tomato Root Colonization by a Pathogenic Strain of Fusarium oxysporum f. sp. lycopersici Discussed in Comparaison to a Non-Pathogenic Strain. New Phytologist, 141, 497-510. http://dx.doi.org/10.1046/j.1469-8137.1999.00365.x

[14] Olivain, C., Trouvelot, S., Binet, MN., Cordier, C., Pugin, A. and Alabouvette, C. (2003) Colonization of Flax Roots and Early Physiological Responses of Flax Cells Inoculated with Pathogenic and Non-Pathogenic Strains of Fusarium oxysporum. Applied and Environmental Microbiology, 69, 5453-5462. http://dx.doi.org/10.1128/AEM.69.9.5453-5462.2003

[15] Lagopodi, A.L., Ram, A.F.L., Lamers, G.E.M., Punt, P.J., Van den Hondel, J.J., Lugtenberg, B.J.J. and Bloemberg, G.V. (2002) Novel Aspects of Tomato Root Colonization and Infection by Fusarium oxysporum f. sp. radicis-lycopersici Revealed by Confocal Laser Scanning Microscopic Analysis Using the Green Fluorescent Protein as a Marker. Molecular Plant-Microbe Interactions, 15, 172-179. http://dx.doi.org/10.1094/MPMI.2002.15.2.172

[16] Lubeck, M., Knudsen, M.B., Jensen, B., Thrane, U., Janvier, C. and Jensen, D.F. (2002) GUS and GFP Transformation of the Biocontrol Strain Clonostachys rosea IK726 and the Use of These Marker Genes in Ecological Studies. Mycological Research, 106, 815-826. http://dx.doi.org/10.1017/S095375620200607X

[17] von der Weid, I., Artursson, V., Seldin, L. and Jansson, J.K. (2005) Antifungal and Root Surface Colonization Properties of GFP-Tagged Paenibacillus brasilensis PB177. World Journal of Microbiology and Biotechnology, 21, 15911597. http://dx.doi.org/10.1007/s11274-005-8123-3

[18] Mansouri, S. and Fakhoury, A.M. (2006) Developing Molecular Tools to Study the Fusarium virguliforme Soybean Interaction. Phytopathology, 96, S72-S73.

[19] Chalfie, M. and Kain, S. (1998) GFP Green Fluorescent Protein Properties, Applications and Protocols. Wiley-Liss, Inc., New York.

[20] Tsien, R.Y. (1998) The Green Fluorescent Protein. Annual Review of Biochemistry, 67, 509-544. http://dx.doi.org/10.1146/annurev.biochem.67.1.509

[21] Rovira, A.D., Newman, E.I., Bowen, H.J. and Campbell, R. (1974) Quantitative Assessment of the Rhizoplane Microflora by Direct Microscopy. Soil Biology and Biochemistry, 6, 211-216. http://dx.doi.org/10.1016/0038-0717(74)90053-4

[22] Hu, M.L., Luo, L.X., Wang, S., Liu, Y.F. and Li, J.Q. (2013) Infection Processes of Ustilaginoidea virens during Artificial Inoculation of Rice Panicles. European Journal of Plant Pathology, 139, 67-77. http://dx.doi.org/10.1007/s10658-013-0364-7

[23] Mebeaselassie, A., Li, L.Y., Feng, A.Q., Zhu, X.Y. and Li, J.X. (2015) Development of a GFP-Expressing Ustilaginoidea virens Strain to Study Fungal Invasion and Colonization in Rice Spikelets. South African Journal of Botany, 97, 16-24. http://dx.doi.org/10.1016/j.sajb.2014.11.013

[24] Parsa, S., Ortiz, V. and Vega, F.E. (2013) Establishing Fungal Entomopathogens as Endophytes: Towards Endophytic Biological Control. Journal of Visualized Experiments, 74, e50360. http://dx.doi.org/10.3791/50360

[25] Smith, S.E. and Read, D.J. (1997) Mycorrhizal Symbiosis. 2nd Edition, Academic Press, San Diego.

[26] Harrison, M.J. (1999) Molecular and Cellular Aspects of the Arbuscular Mycorrhizal Symbiosis. Annual Review of Plant Physiology and Plant Molecular Biology, 50, 361-389. http://dx.doi.org/10.1146/annurev.arplant.50.1.361

[27] Parniske, M. (2000) Intracellular Accommodation of Microbes by Plants: A Common Development Program for Symbiosis and Disease? Current Opinion in Plant Biology, 3, 320-328. http://dx.doi.org/10.1016/S1369-5266(00)00088-1

[28] Strack, D., Fester, T., Hause, B., Schliemann, W. and Walter, M.H. (2003) Arbuscular mycorrhiza: Biological, Chem- 
ical, and Molecular Aspects. Journal of Chemical Ecology, 29, 1955-1979. http://dx.doi.org/10.1023/A:1025695032113

[29] Lorang, J.M., Tuori, R.P., Martinez J.P., Sawyer, T.L., Redman, R.S., Rollins, J.A., et al. (2001) Green Fluorescent Protein Is Lighting up Fungal Biology. Applied and Environmental Microbiology, 67, 1987-1994. http://dx.doi.org/10.1128/AEM.67.5.1987-1994.2001

[30] Oren, L., Ezrati, S., Cohen, D. and Sharon, A. (2003) Early Events in the Fusarium verticillioides-Maize Interaction Characterized by Using a Green Fluorescent Protein Expressing Transgenic Isolate. Applied and Environmental Microbiology, 69, 1695-1701. http://dx.doi.org/10.1128/AEM.69.3.1695-1701.2003

[31] Visser, M., Gordon, T.R., Wingfield, B.D., Wingfield, M.J. and Viljoen, A. (2004) Transformation of Fusarium oxysporum f. sp. cubense, Causal Agent of Fusarium Wilt of Banana, with the Green Fluorescent Protein(GFP) Gene. Australasian Plant Pathology, 33, 69-75. http://dx.doi.org/10.1071/AP03084

[32] Li, C.Y., Chen, S., Zuo, C.W., Sun, Q.M., Ye, Q., Yi, G.J. and Huang, B.Z. (2011) The Use of GFP Transformed Isolates to Study Infection of Banana with Fusarium oxysporum f. sp. cubense Race 4. European Journal of Plant Pathology, 131, 327-340. http://dx.doi.org/10.1007/s10658-011-9811-5

[33] Damm, U., Brune, A. and Mendgen, K. (2003) In Vivo Observation of Conidial Germination of the Oxi-Anoxic Interface and Infection of Submerged Reed Roots by Microdochium bolleyi. FEMS Microbiology Ecology, 45, $293-299$. http://dx.doi.org/10.1016/S0168-6496(03)00161-2

[34] Gao, K.X. and Mendgen, K. (2006) Seed-Transmitted Beneficial Endophytic Stagonospora sp. Can Penetrate the Walls of the Root Epidermis, but Does Not Proliferate in the Cortex, of Phragmites australis. Canadian Journal of BotanyRevue Canadienne de Botanique, 84, 981-988.

[35] Zvirin, T., Herman, R., Brotman, Y., Denisov, Y., Belausov, E., Freeman, S., et al. (2010) Differential Colonization and Defence Responses of and Susceptible Melon Lines Infected by Fusarium oxysporum Race 1.2. Plant Pathology, 59, 576-585. http://dx.doi.org/10.1111/j.1365-3059.2009.02225.x

[36] An, Q.L., Yang, X.J., Dong, Y.M., Feng, L.J., Kuang, B.J. and Li, J.D. (2001) Using Confocal Laser Scanning Microscope to Visualize the Infection of Rice Roots by GFP-Labelled Klebsiella oxytoca SA2, an Endophytic Diazotroph. Acta Botanica Sinica, 43, 558-564.

[37] Eynck, C., Koopmann, B., Grunewaldt-Stoecker, G., Karlovsky, P. and von Tiedemann, A. (2007) Differential Interactions of Verticillium longisporum and V. dahliae with Brassica napus Detected with Molecular and Histological Techniques. European Journal of Plant Pathology, 118, 259-274. http://dx.doi.org/10.1007/s10658-007-9144-6

[38] Abdellatif, L., Bouzid, S. and Vujanovic, V. (2007) New Plant Growth Promoting Fungal Endophytes Reprogram Wheat and Provide Disease Resistance. Plant Canada-Growth for the Future (Proceedings), Saskatoon, SK, Canada, 137-139. 